\title{
MARKETING OF SURVEILLANCE TECHNOLOGY IN THREE AGEING COUNTRIES
}

\author{
VERMEER, Yvette ${ }^{\text {a1 }}$; HIGGS, Paula2 ${ }^{\text {; CHARLESWORTH, Georgina }}{ }^{\text {b3 }}$ \\ a UCL, Faculty of Brain Sciences, Division of Psychiatry, Maple House,6th Floor,149 Tottenham Court Rd, \\ London W1T 7NF, United Kingdom \\ ${ }^{b}$ UCL, Faculty of Brain Sciences, Department for Clinical, Education, and Health Psychology, 1-19 Torrington \\ Place, London, WC1E 7HB, United Kingdom \\ ${ }^{1}$ Yvette Vermeer, y.vermeer@ucl.ac.uk, Early Stage Researcher, \\ ${ }^{2}$ Paul Higgs, p.higgs@ucl.ac.uk, Professor. \\ ${ }^{3}$ Georgina Charlesworth, G.charlesworth@ucl.ac.uk, Associate Professor, \\ Interdisciplinary Network for Dementia Using Current Technology (INDUCT)
}

\begin{abstract}
Purpose - To review marketing materials of surveillance products for people with dementia and their carers in three ageing countries, as part of a dementia-technology media analysis.

Design/methodology/approach - An online environmental scan was conducted using search terms for surveillance technologies (ST) and dementia through a google search focused on the United Kingdom, Sweden, and the Netherlands. Data were extracted on the products' and websites' marketing messages from consumer and marketer perspectives.
\end{abstract}

Findings - Information was gathered for 382 product websites, of which 242 met eligibility criteria. The majority of products come from the United Kingdom. In the United Kingdom and Sweden, the companies behind the websites appeared to be mainly 'cottage industries' which focus on selling ST. In contrast, sellers in the Netherlands included a more balanced mixture of small, medium and large companies. In all three countries the website messaging focussed on the need to manage safety concerns, without considering privacy or consent.

Implication/value - Contrary to the perception of future dependence on technology, the ST sector seems to be a niche market. The media messages, equating people with dementia with animals and children, are at odds with initiatives that strive for dignity and dementia friendliness.

Originality/value - No previous study is known to have explored media messages from websites that market surveillance technology for people with dementia.

Keywords surveillance, safety, technology, dementia, carers, marketing, cottage industries, environmental scan, review.

Paper type Research paper 


\section{Introduction}

The use of technology designed to help ageing populations, especially those with dementia, is rising in social importance. The EU identifies dementia as a societal challenge and highlights the necessity for research on technology-related care (European Commission 2015; European Parliament 2011). Technology is perceived as promising, and significant investments have been made to advance older people's access to, and uptake of, technological products (European Commission 2007; European Commission 2015). On a national level, social policies and market priorities seek to facilitate 'ageing in place' through the use of technology (Kubitschke et al. 2010; van Hoof et al. 2010) which delays institutionalisation; encourages people to remain in their own home in later life (Brittain et al. 2010); saves costs (Duff \& Dolphin 2007) and reduces caregiver burden (McHugh et al. 2012). Accordingly, technology, as part of healthcare delivery for people living with dementia, is expected to grow in Europe (Kubitschke et al. 2010; Dutta et al. 2015; WHO, 2012; van Hoof et al. 2010; EPRS 2016).

\section{Surveillance Technology}

Surveillance Technologies (STs) are devices which monitor movements with the intention to cost-effectively support health and independence (Woolrych et al. 2013). ST has particular relevance for family carers of people with dementia (Berridge et al. 2014). ST can be generally described as comprising "monitoring systems that can allow for 24-hour supervision by carers" (Kenner 2008), with specific technologies including, but not limited to: monitoring devices, personal and social alarms, telecare, electric tagging and tracking, and Global Positioning System (Landau \& Werner 2012; Percival \& Hanson 2006; Robinson et al. 2007; Niemeijer 2015; Mental Welfare Commission for Scotland, 2005). ST can be used to monitor people with dementia so that a carer can intervene as appropriate to increase safety (Niemeijer 2015).

\section{'Ageing in place' in the United Kingdom, Sweden and the Netherlands}

In common with many other nations, the United Kingdom (UK), Sweden (SWE), and the Netherlands (NL) all have ageing populations. Projections show that life expectancy for 65 year olds is similar in each of these countries (UK 17.9; NL 18.2; SWE 19.8), and the 
proportion of older adults who live alone is also similar (UK 32\%; NL 32.2\%; SWE 39\%) (Eurostat 2015; Office for National Statistics 2017). As these societies age, the number of vulnerable people requiring long-term care also increases (Berridge et al. 2014; Niemeijer 2015). A European study found a variety of reasons for family carers seeking to place the person living with dementia whom they care for in a care home, with common reasons including care dependency and caregiver burden (Afram et al. 2014). The use of technology has been identified as a potential solution to help carers and people with dementia to remain living in their own home, lighten the care burden, and to support caregiving (Berridge et al. 2014; Kubitschke et al. 2010; Bharucha et al. 2009; Cahill et al. 2007; Kenner 2008; Pollack 2005; Topo 2009).

In the UK, the government ageing agenda has an eye to cost (Duijnstee 1992; Goins et al. 2002; Kodner 2003; Walker 2008). The UK National Health Service and Community Care Act (1990) highlighted the need to incorporate market forces in the delivery of services that facilitate 'ageing in place' as opposed to more institutionalised care settings (WAG, 2011; Department of Health, 2006, 2009; Department of Health Social Services and Public Safety, 2011; Phillipson, 1998; The Scottish Government., 2010). Despite the differences in health care systems, the Netherlands and Sweden also have national health and social policies that promote the move from institutional care to 'ageing in place' (Kümpers 2005; Wimo et al. 1999). The capacity to leverage technology for increased well-being is measured by the 'Networked Readiness Index', which is similar to those in the UK, Sweden and the Netherlands (Dutta et al. 2015).

\section{Marketing Surveillance Technology}

Marketers have begun to recognize the importance of ST as a market and, accordingly, there has been an increase in numbers of such technological products being sold, particularly through online platforms (Rialle et al., 2008; Robinson, et al., 2009; Wan, et al., 2016). The knowledge base on how ST products for dementia are marketed is very limited, with little beyond the work of Kenner (2008) who describes an 'aging enterprise' which constitutes technologies as part of a privatized consumer healthcare trend (p.262); a trend which might not be influenced by older adults, but rather by other external pressures. These pressures 
include discourses that influence our understanding about diseases, as well as those affected by them, and which are often framed and negotiated through media messages (Clarke 2006; Collin \& Hughes 2011; Lyons 2000; Seale 2003; Williamson \& Skinner 2011). Clarke (2006) described the importance of recognizing the relations between media, disease representations, and the interests of powerful organisations who play on underlying fears to market products that offer a solution (Fuller 1998). Clarke, (2006) called for a 'dementia media analysis' (Miller et al., 2012; Kleebpung 2010) to identify and assess what cultural stereotypes and values underlie the media messages that describe and portray people with dementia.

Aim

The aims of this paper are to (1) investigate the online market for surveillance products for people with dementia in three comparable, ageing countries (UK, SWE, and NL), and to describe the marketers' characteristics; and (2) to respond to the call for dementia media analysis by exploring the marketing messages in online advertisements for surveillance technologies for people with dementia.

\section{Method}

\section{Environmental scan}

To identify surveillance products used in dementia care, and explore media messaging used by marketers, environmental scan methodology was used, adapted from a procedure of Choo and colleagues (Choo, Auster, 1993; Choo, 1999, 2001). Environmental scanning is an information viewing, seeking and organizational learning strategy (Aguilar, 1967; Choo \& Auster, 1993; Choo, 2001) through which companies get to 'know' the market in which they are situated and are able to effectively respond (Choo 1993). Originating in a company context, health care researchers have started using environmental scans (Graham et al. 2008); however, there is not, as yet, a standardised approach to environmental scanning (Choo \& Auster, 1993; Choo, 1999, 2001). A common approach is to seek answers to a set of pre-defined questions regarding the product of interest (Graham et al. 2008).

To provide information on the ST market for people with dementia and their carers, the environmental scan detailed in this paper entailed (1) an online product search (2) selection 
of eligible products through application of pre-defined eligibility criteria (3) extraction of product data and marketing messages through answering a set of questions for each eligible product (4) data synthesis through both qualitative and quantitative means.

\section{Search strategy}

An internet search for surveillance products was carried out using the Google search engine. Search terms and their synonyms are shown in English in table 1. Each search term was translated into Dutch and Swedish for product searches in the Netherlands and Sweden respectively (translated search teams available on request).

Table 1 Search terms (English)

\begin{tabular}{|l|l|}
\hline Search word & Synonyms \\
\hline $\begin{array}{l}\text { Surveillance } \\
\text { Technology }\end{array}$ & $\begin{array}{l}\text { Surveillance technologies, devices, products, assistive, GPS, tracking, tagging, } \\
\text { tracker, track, monitor, locate, locator }\end{array}$ \\
\hline Dementia & Alzheimer, Alzheimer's, person with dementia, people with dementia \\
\hline Carer & informal caregiver, caregiver, Family caregiver, family carer \\
\hline UK & United Kingdom, England, Great Britain \\
\hline AND ...OR & $\begin{array}{l}\text { Safety, independence, empowerment, risk, danger, alert, peace of mind, consent, } \\
\text { informed consent }\end{array}$ \\
\hline
\end{tabular}

\section{Eligibility criteria}

The product web-descriptions identified in the online search were assessed for eligibility using pre-defined eligibility criteria.

The inclusion criteria were:

- technological device that tracks and/or alerts;

- marketing makes reference to dementia, Alzheimer's or similar

- product can be used by a person with dementia or a carer;

- marketing website based in the Netherlands, United Kingdom or Sweden;

- marketing of the product targets care homes, institutions, people with dementia or carers.

Exclusion criteria were: 
- 'non-technical' products

- manufacturer not involved in retail

- traders between the manufacturer and marketing website

- website designers

- webpages marketing second-hand, previously used, or previously owned goods

Three researchers (English, Dutch and Swedish) were involved in developing the search criteria and screening the websites for information. Every website with at least two of the keywords was selected for further analysis. The researchers placed field notes in the data set, and provided descriptions of what was portrayed on websites. When a product was entered, the reviewer would screen for duplicates by the excel search function in the data set. If a duplicate was found, the new product would not be entered. However, there was a possibility that similar products were displayed by alternative websites under different circumstances. Therefore, the reviewer screened again the data set to remove repetition and irrelevant products (for example, non-technological products sold on Amazon). This removal was carried out twice after the exclusion criteria. Duplicates of products were included only if they were provided by alternative websites using different marketing techniques.

\section{Data extraction}

A draft data extraction tool was devised, based on domains relevant to characteristics of products and marketers, and the anticipated information needs of potential users. The draft tool was validated through discussion with researchers from a 'dementia and technology network' (INDUCT) and piloted by the first author after which additional subcategories (market share and growth) were added. The final data extraction tool covered 9 domains, extracting information on: identification; marketer characteristics; product functional availability; target market, sales; safety; privacy and portrayals (Table 2).

The extracted data was entered into an excel spreadsheet, in formats suitable for the nature of the data. Data types included nominal, categorical, numerical and qualitative formats (table 2). Qualitative data included quotations from websites. Data were collected over a 
period of one year, between October 2016 and October 2017 with data regarding product prices gathered on the same day in August 2017.

When websites did not provide information about the marketer that provided the product (e.g. size of marketer, country origin, number of employees), additional public-domain information was gathered online, for example from Linkedln. Classification of the size of the marketing organisation was based on the number of employees within that organisation, with 'cottage industry' defined as "a small-scale informally organized industry run from home" (Investopedia LLC 2017) and operationalised as "online web shop indicative of; its location being a private house, a private phone number communicated, or listed with one employee usually described as the owner". Small scale companies were defined as having a maximum of 10 employees; small-medium between 10 and 50, medium-large between 50 and 200; large more than 200 employees.

Table 2 Data extraction items and data types

\begin{tabular}{|l|l|l|l|}
\hline & Domain & Item & Data type \\
\hline 1 & Identifiers & $\begin{array}{l}\text { Product name } \\
\text { Company / organisation name }\end{array}$ & $\begin{array}{l}\text { Nominal } \\
\text { Nominal }\end{array}$ \\
\hline 2 & $\begin{array}{l}\text { Marketer } \\
\text { characteristics }\end{array}$ & Organisation size & $\begin{array}{l}\text { Categorical (cottage industry, small, small } \\
\text { medium, medium, large) } \\
\text { Numerical }\end{array}$ \\
\hline 3 & $\begin{array}{l}\text { Product } \\
\text { function }\end{array}$ & $\begin{array}{l}\text { Main function } \\
\text { Additional information }\end{array}$ & $\begin{array}{l}\text { Categorical (track, alarm, track \& alarm) } \\
\text { Qualitative }\end{array}$ \\
\hline 4 & Availability & $\begin{array}{l}\text { Availability in Sweden, UK, } \\
\text { Netherlands? } \\
\text { Country of product origin }\end{array}$ & $\begin{array}{l}\text { Categorical (Yes/No) } \\
\text { Categorical (Sweden, UK, Netherlands, } \\
\text { Other) } \\
\text { Categorical (online, in store, both, other) }\end{array}$ \\
\hline 5 & Target market & Availability online / in store & $\begin{array}{l}\text { Target purchasers } \\
\text { Tategorical (consumer, care home, } \\
\text { company, other) } \\
\text { Categorical (person with dementia, carer, } \\
\text { unclear) }\end{array}$ \\
\hline 6 & Sales & $\begin{array}{l}\text { Price }{ }^{+} \\
\text {Additional information }\end{array}$ & $\begin{array}{l}\text { Numerical } \\
\text { Qualitative }\end{array}$ \\
\hline 7 & Safety & Safety messaging & $\begin{array}{l}\text { Categorical (User activated alert, User } \\
\text { alerted, Alerts carer, Alerts both, other } \\
\text { Qualitative }\end{array}$ \\
\hline 8 & Privacy & Additional explanation & $\begin{array}{l}\text { Categorical (user only, carer only, user \& } \\
\text { carer, } \\
\text { Qualitative }\end{array}$ \\
\hline & Access to data & $\begin{array}{l}\text { Categorical (Yes/No) } \\
\text { Nominal }\end{array}$ \\
\hline
\end{tabular}


+ If the origin of a product was unclear, it was classified according to the country in which it could be purchased.

+ + Purchase price excluded monthly fees or shipping costs.

Data analysis

Price conversions were made into pounds and the Excel 'AVERAGE' function was used for calculating the mean purchase prices. The 'COUNTIF' function was used to summarise the frequency of specific words in nominal data (e.g. 'safety'). For categorical items the SUM function was used.

\section{Findings}

In total, 382 products were identified online. After the application of the eligibility criteria and removal of duplicates, 242 products remained. Reasons for exclusion included: being 'non-technical' products e.g. identification bracelets without tracking facility; networking facility without detection monitors (e.g. for temperature, light or fire'). In descending order of frequency, the identified products originated from: the UK, Australia, the United States, Sweden and the Netherlands.

Price

The purchase price of ST displayed ranges from $f 0$ to $f 654$ in the three countries, with similar products priced differently by different providers. Thirteen products were under $£ 10$. The headline price displayed often included extras (i.e. shipping costs, monthly fees). However, the mean price is unknown because many websites displayed neither prices, nor included extras.

\section{Marketers}




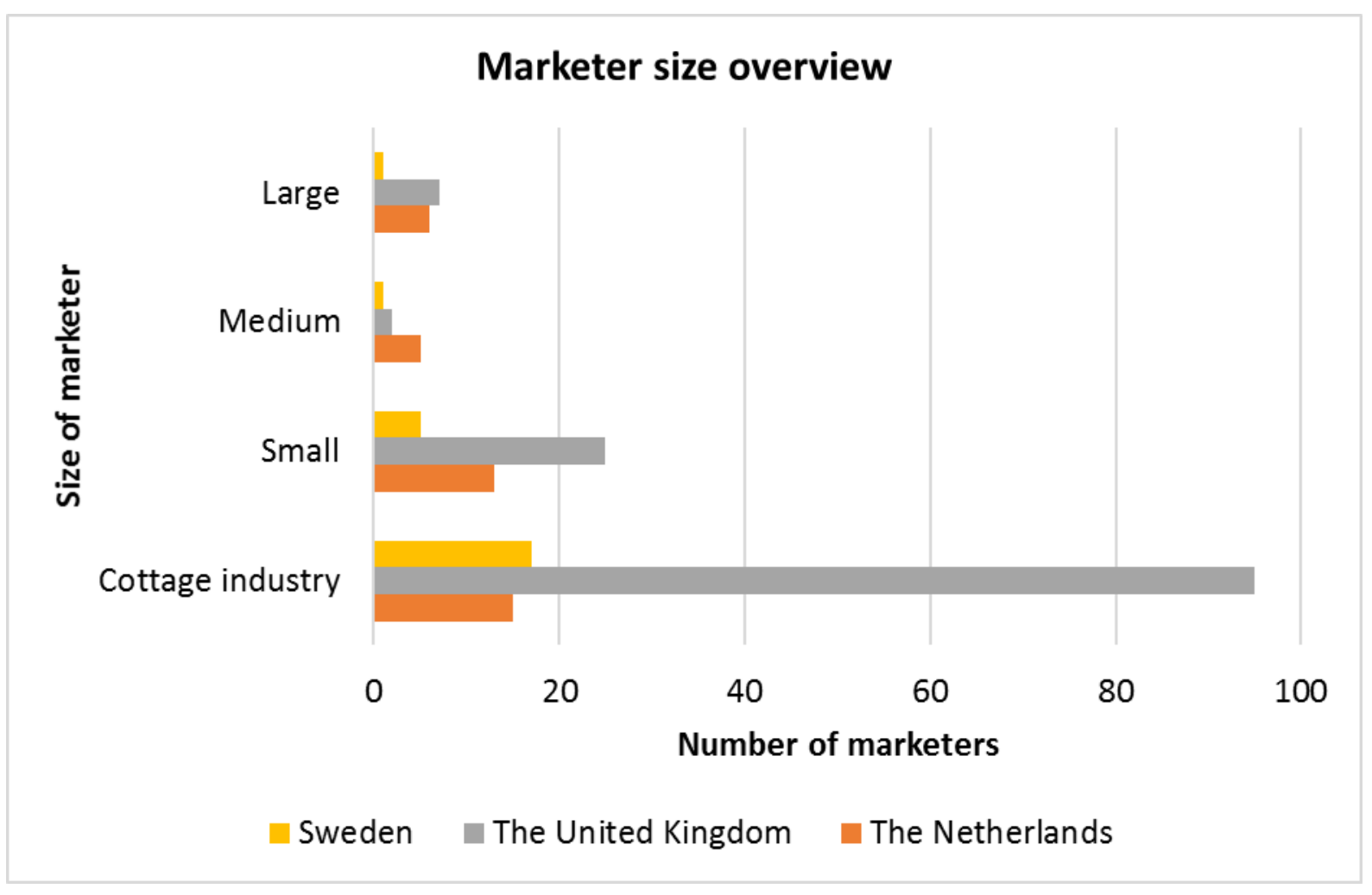

Figure 1 What is known about the size of the marketer?

Figure 1 displays the response to the question "what is the size of the marketer". The 'cottage industry' category was the largest single category in all three countries, marketing through single-handed online web shops or companies with up to ten employees. Whereas the majority of ST marketers in the UK and Sweden were cottage industries, there was a different pattern in the Netherlands where there was morebalance across size of company. Many marketers in the dataset made unsubstantiated claims to be the market leader.

Safety

In scanning the web-descriptions for "what is mainly communicated about what the product does for safety", two main types of products were elicited; products that 'detect' and those that 'alert'. The latter required that the person with dementia should push an alert button in case of emergency, or that somehow the carer was made aware of an emergency, although there was generally scant detail on how, when, where or to whom alerts would be raised. Most of the detectors did not send notifications. However, some products both detected 
and alerted, for example a tracker watch that could notify the carer with information about the recipients' location and health status.

"The .... can act as both a locator for keys and bags or a tracking device for a loved one, to help keep them safe if they wander" Location tracker - cottage industry 1.

Location finding may require the carer to access real-time monitoring on a computer or phone (Kenner 2008; Mulvenna et al. 2017).

"Ideal for monitoring: pets (e.g. dogs / cats / horses etc...), children / teenagers of all ages \& abilities, vulnerable adults or frail elderly who may misuse the SOS \& on / off buttons e.g. autism, Alzheimer's / dementia sufferers" SOS button - cottage industry 2. A minority of products were described as 'preventing risk'; however, little or no explanation was provided on the mechanism for this.

Marketing by keywords and portrayals

\section{What keywords are advertised?}

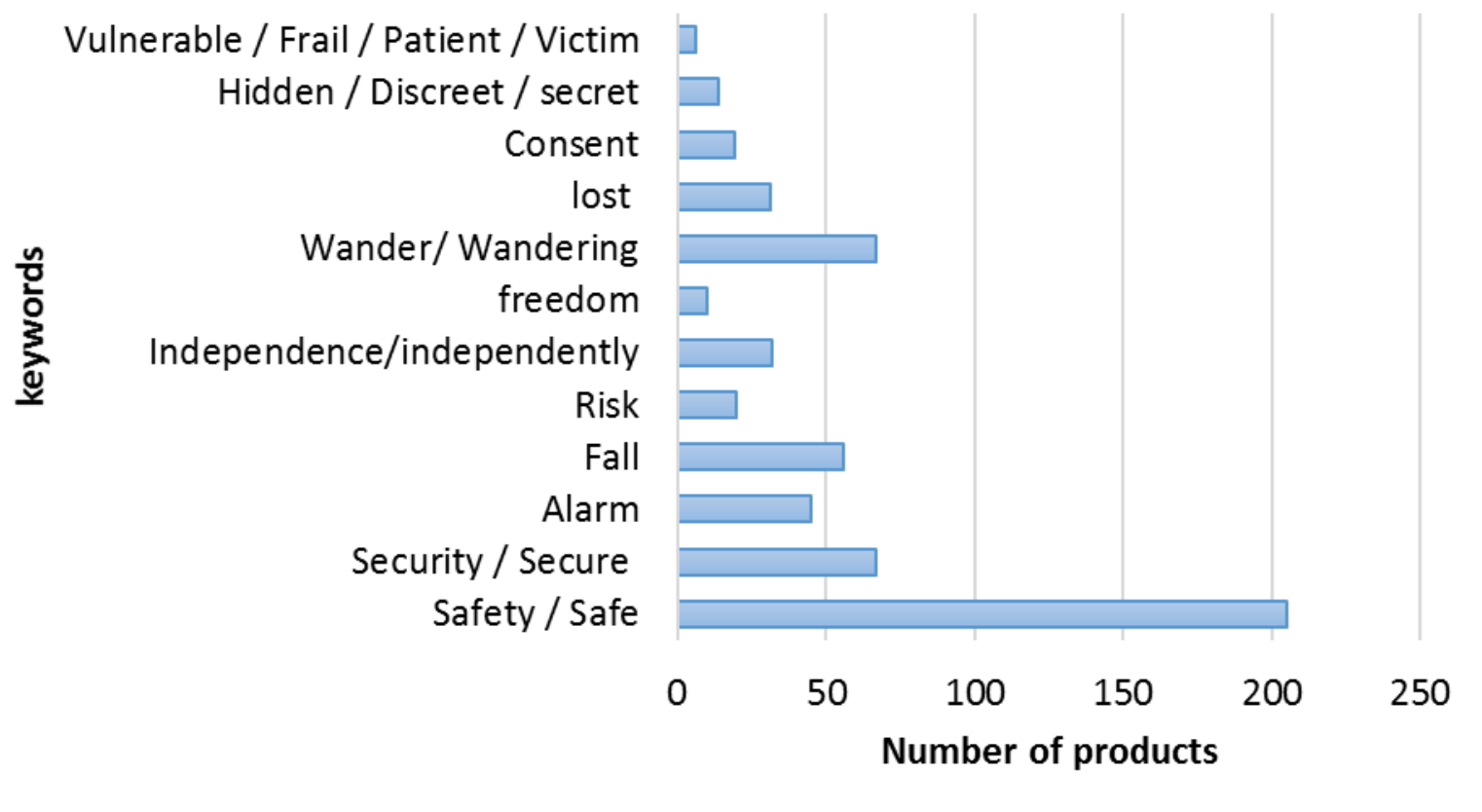

Figure 2: The keywords advertised on providers' web-descriptions 
Figure 2 illustrates the key descriptors used on websites. The greatest emphasis was on safety and security. The target problems were wandering, being lost, and falls. There were differences in the diversity of keywords used in each of the three countries. In Sweden, keywords were descriptive of 'spy' and 'camera'. In the Netherlands 'sensor' was a common keyword. In the UK words such as 'ethics' and 'consent' were used, which remarkably were not used in Sweden and the Netherlands. However, the word 'consent' was not used in relation to having have approval to use ST on a person with dementia. Instead, words such as 'hidden', 'discreet' and 'secret' were used, indicating covert surveillance.

Keywords were often accompanied by striking visuals of people with dementia, pets, children, and possessions, either kept safe through ST use, or portrayals of being lost and harmed through non-use of ST. No major between-country differences were identified in visual portrayals.

\section{Marketing target}

There were no examples of marketing messages being targeted at people living with dementia. Instead, messages were aimed at families and carers, researchers or organisations involved in social care provision:

“... provides an ideal way for families and caregivers to keep track of the people they love. Ideal for children.... and seniors who value their independence. It's all about having peace of mind when you're not there with them" location tracker - cottage industry 3.

"Our customers include: dementia \& Alzheimer's patients, stroke patients, local councils, care homes, schools, rehabilitation centers, dementia research groups, universities, cautious parents, travelers / employers" location tracker, cottage industry 4.

\section{Privacy}

Most products identified through the environmental scan required data-sharing. The majority reported that carers would receive data, such as the location of the person with dementia. However, the second largest group involved data-sharing with third parties (e.g. online cloud storage, alarm centre). 
"GPS personal alarm and its 24/7 response service lets you to carry on with your life knowing that there is help available at the press of a button" location tracker with SOS button - Cottage industry 5

Few ST reported that they provided the person with dementia with the data of their location or gave them instructions to guide them home although this is an expressed need of people with dementia (Robinson et al. 2009).

\section{Discussion}

This paper represents the first media analysis of online marketing of surveillance products for use with people with dementia. The key finding about marketers was that they were predominantly 'cottage industries', especially in the UK. In all three countries, the products being marketed were generally unsophisticated, able to either detect or alert, rather than both. Product descriptions emphasised safety and security, referencing risk situations such as wandering, falling or being lost, even where the product had no function that would prevent such risk. Advertising was targeted at carers or service providers, and not people with dementia. People with dementia were commonly portrayed as a 'problem to be managed', and consideration of ethical issues (such as freedom to choose, consent and covert surveillance), whilst varying by country, was largely absent.

\section{Niche market?}

Huge investments have been made in the research and development of telehealth and telecare (Department of Health 2008; Woolrych et al. 2013), including the Whole System Demonstrator randomised controlled trial (Steventon et al., 2013) and NHS testbeds such as 'Technology Integrated Health Management for dementia' (Galea et al., 2017). Yet, counterintuitively, the majority of marketers identified in the environmental scan were 'cottage industries' suggesting a 'niche market'. This finding may be due to data collection being by product rather than by market-share. The UK has a large home-care social alarms market, and is a significant adopter of telecare (Taylor 2012; Goodwin 2010; Kamalasekar 2010; Gibson et al. 2016). People who meet the eligibility standards for social care can access pendant alarms commissioned by local authorities (Berridge et al. 2014). In Sweden, municipalities pay for alarm installation, and users contribute to this monthly service. There is a mix of public and private sector provision, with private manufacturers financing much of 
the research and development into advanced telecare (Berridge et al. 2014). In the Netherlands, the social security system, municipalities, well-being organisations, and other home-care organisations provide alarms but payments are not standardised but vary according to who is using the technology, and for what purpose (Kubitschke et al. 2010).

\section{Not 'fit for purpose'?}

The number of websites claiming to be 'market leader' suggests that a certain amount of creative licence was employed in advertising, and it was clear that many products had been re-purposed' for the dementia market having originally been designed for a different use.

People living with dementia have expressed the need for technologies to have a simple user interface that can be tailored to individual needs and skills, that allows people with dementia to engage in everyday activity and allows carers to have a break knowing that they will receive an alert if risk situations arise (Dixon, 2016), such as personalised notifications when the person with dementia leaves an area of safety (Phillips \& Zhao 1993; Schulz et al. 2012; Schulz 2012). However, the majority of identified products could either detect or alert, or required real-time monitoring.

Carers have concerns over false alarms (Dixon, 2016; Niemeijer 2015; Hall et al. 2017), privacy (Dixon, 2016), and data-sharing with other parties (Robinson et al. 2007; Fisk 2015; Niemeijer 2015) yet most products involved third parties such as call-centres. Product descriptions included only limited information on functionality, and focused instead on risks such as falling, wandering and getting lost. Whilst promotion of ST products emphasises independence and safety (Kenner 2008), this outcome has not necessarily been established through research (Futrell \& Melillo, 2002; Hughes, 2008a, 2008b; Marr, 1989; MWCS, 2005; Moffat, 2008; Nelson et al., 2004; Niemeijer, 2015; Plastow, 2006; Robinson et al., 2007; Sävenstedt, et al., 2006; Welsh, et al., 2003). Alerts from ST devices can signal when a fall happens, but do not avert the fall. The question posed by Niemeijer and colleagues (2015, p.124) therefore remains unanswered “... does ST actually offer more security?”.

Throughout the EU there is an expectation that businesses to not misrepresent their products when advertising to consumers (Collins 2005; Van Boom 2015). The 'Unfair Commercial Practices' directive underpins the national advertising authorities in the UK, the 
Netherlands and Sweden (Advertising Standards Authority Ltd 2018; Netherlands Enterprise Agency 2018; Reklamombudsmannen 2017). Consumers in the three countries can submit complaints about misleading advertisements, and companies are penalized where complaints are upheld. However, problematic practices are not always addressed (Van Boom 2015) and in a media-rich online environment consumers may not be aware of being misled (Van Boom 2015; Mitra et al. 2008).

\section{Portrayals of dementia}

The portrayal of people with dementia as a 'problem to be managed' has been highlighted in previous research (Rozanova et al. 2016). Placing people with dementia in the same class as wallets, keys, young children, dogs and/or prisoners is reminiscent of the 'objectification' described in healthcare prior to the person-centred care movement, and is concordant with 'abjection'; a defining feature of the social imaginary of the fourth age (Higgs \& Gilleard, 2014). Marketers may have simply adapted existing advertising materials when dementia care was identified as a potential new market, assuming a lack of autonomy and decisionmaking capacity in line with the 'empty shell' portrayal of dementia (Alzheimer Europe, 2013).

No marketing was directed at the person with dementia themselves even though people in early stages of dementia may choose to engage with surveillance technology, for example actively seeking out devices such as ST bracelets (Niemeijer 2015), safe in the knowledge that they can be monitored by a 'supportive other'. In these circumstances, surveillance technology can indeed help to maintain independence (Essén, 2008) and freedom (Dorrestijn \& Verbeek 2013), reflecting Foucault's (2000) notion of freedom incorporating an individual's conscious choice to use technology.

There was between-country discrepancy in use of terms such as 'ethics' and 'consent', but none of the marketers considered personal choice of the person with dementia. Little information was provided on the acceptability of surveillance devices from the perspective of people with dementia. Whilst most products are solely designed for, and used by, carers (Topo 2009; Demers et al. 2009), this should not mean that the perspective of the person with dementia should be ignored. Some people may not like having an unfamiliar device 
attached to them (McShane et al., 1998; Wan et al., 2016) and may take off items such as pendants or bracelets. As Niemeijer and colleagues (2015) observed, when an ST bracelet is taken off, it no longer does its job. This may explain the emphasis on 'hidden' devices for covert monitoring.

Media representations of dementia can influence interactions with people with dementia and make a difference to the utilisation of health care resources (Kessler \& Schwender 2012). Bodies now exist that review and counteract media messages. For example, the Glasgow Media Group (GMG) reviewed various claims used in the media (e.g. issues of war, representations of AIDS, communications of risk), and how this impacts negatively on certain groups (e.g. refugees, disabled people) (Briant, Watson \& Philo 2011; Eldridge 2000). Whilst members of the GMG have worked, and continue to work, to publicise their critiques (Eldrigde 2000), unhelpful media coverage of dementia keeps on growing (Kessler \& Schwender 2012).

\section{Implications for stakeholders}

There are important implications from this study for a range of stakeholders including manufacturers, marketers, the media, and researchers, in addition to all those living with dementia. Families, and people living with dementia themselves, should consider the power of media messaging which may present out-of-date and inappropriate technology as 'tried and tested' or 'market leading', or may emphasise safety-enhancement or risk reduction for products that provide only 'after the event' alerts. Organisations that support people with dementia and their families could play a role in highlighting some of the decisions that need to be made, such as whether a product has the appropriate combination of detection and alerting functions to suit an individual's particular circumstances. In addition, support organisations could also highlight ethical considerations of surveillance, for example whether a person with dementia themselves is choosing to use technology, or whether carers are making choices in circumstances that do not yet require 'best interests' decisionmaking (for an illustration of carer fears over safety leading to autonomy restriction see Graneheim et al. 2001). Manufacturers and marketers should pay closer attention to the potential market of people in the early stages of dementia who can express their own needs 
and preferences. Furthermore, marketers and the media should be made aware of the potential for stigma-exacerbation from media messages that objectify people with dementia.

\section{Conclusion}

This paper draws attention to an emerging issue of ST for people with dementia. The marketing of ST does not take into consideration the needs of people with dementia themselves. Marketing of surveillance technologies raises issues of rights, autonomy, dignity, privacy and consent but all too often the marketers' messages run counter to the maintenance of dignity in later life.

\section{References}

Advertising Standards Authority Ltd, (2018). "Advertising Standards Authority", Available at https://www.asa.org.uk/ (accessed April 24, 2018).

Afram, B., Stephan, A. \& Verbeek, H., (2014), "Reasons for institutionalization of people with dementia: informal caregiver reports from 8 European countries". Journal of the American Medical Directors Association, 15(2), pp.108-116.

Aguilar, F.J., (1967), Scanning the business environment, Macmillan.

Alzheimer Europe, (2013), "Wandering", available at http://www.alzheimereurope.org/Living-with-dementia/Caring-for-someone-with-dementia/Changes-inbehaviour/Wandering\#fragment1 (accessed May 26, 2017).

Berridge, C., Furseth, P. I., Cuthbertson, R., \& Demello, S. (2014), "Technology-based innovation for independent living: policy and innovation in the United Kingdom, Scandinavia, and the United States". Journal of Aging \& Social Policy, 26(3), 213-228.

Bharucha, A. J., Anand, V., Forlizzi, J., Dew, M. A., Reynolds, C. F., Stevens, S., \& Wactlar, H. (2009), "Intelligent assistive technology applications to dementia care: current capabilities, limitations, and future challenges". The American Journal of Geriatric Psychiatry, 17(2), 88104.

van Boom, W.H., (2015), Unfair Commercial Practices. SSRN Electronic Journal.

Briant, E., Watson, N. \& Philo, G., (2011), "Bad news for disabled people: How the newspapers are reporting disability", Project Report. Strathclyde Centre for Disability Research and Glasgow Media Unit, University of Glasgow, Glasgow, UK. 
Brittain, K., Corner, L., Robinson, L., \& Bond, J (2010), "Ageing in place and technologies of place: The lived experience of people with dementia in changing social, physical and technological environments". Sociology of Health and IIIness, 32(2), pp.272-287.

Cahill, S., Macijauskiene, J., Nygård, A. M., Faulkner, J. P., \& Hagen, I. (2007), "Technology in dementia care". Technology and Disability, 19(2, 3), 55-60.

Choo, C.W., (2001), "Environmental scanning as information seeking and organizational learning". Information research, 7(1), pp.7-1.

Choo, C.W., (1999), "The Art of Scanning the Environment". Bulletin of the American Society for Information Science and Technology, 25(3), pp.21-24.

Choo, C. W., \& Auster, E., (1993), "Environmental Scanning: Acquisition and Use of Information by Managers". Annual Review of information Science and Technology (Arist), 28, pp.279-314.

Clarke, J., (2006), "The case of the missing person: Alzheimer's disease in mass print magazines" 1991-2001. Health Communication, 19(3), pp.269-276.

Collin, J. \& Hughes, D., (2011), "The silent killer in media stories: representations of hypertension as health risk factor in French-language Canadian newspapers". Health, Risk \& Society, 13(6), pp.577-592.

Collins, H., (2005), "The unfair commercial practices directive". European review of contract law, 1(4), pp.417-441.

Demers, L., Fuhrer, M. J., Jutai, J., Lenker, J., Depa, M., \& De Ruyter, F. (2009), "A conceptual framework of outcomes for caregivers of assistive technology users". American Journal of Physical Medicine \& Rehabilitation, 88(8), 645-655.

Department of Health. (2009), "Living well with dementia: a national strategy". Department of Health and Social Care, UK, 3 February 2009.

Department of Health. (2008), "Carers at the heart of 21st-century families and communities: a caring system on your side". pp. 1-168. Department of Health London, 10 June 2008.

Department of Health, (2006), Our health, our care, our say: a new direction for community services, The Stationery Office, 2006.

Department of Health Social Services and Public Safety, (2011), "Improving dementia services in Northern Ireland: a regional strategy", 8 November 2011.

Dixon, J., 2016. "Technology Integrated Health Management", University of Surrey, 5 G Innovation Centre, 3 June 2016.

Dorrestijn, S. \& Verbeek, P., (2013), "Technology, wellbeing, and freedom: The legacy of utopian design". International Journal of Design, 7(1). 
Duff, P. \& Dolphin, C., (2007), "Cost-benefit analysis of assistive technology to support independence for people with dementia-Part 2: Results from employing the ENABLE costbenefit model in practice". Technology and Disability, 19(2,3), pp.79-90.

Duijnstee, M., (1992), "De belasting van familieleden van dementerenden", Doctoral dissertation, Instituut voor Zorg en Welzijn, Utrecht, 1992.

Dutta, S., Geiger, T. \& Lanvin, B., (2015), "The global information technology report 2015. World Economic Forum", 1(1), pp.80-85.

Eldridge, J., (2000), "The Contribution of the Glasgow Media Group to the Study of Television and Print Journalism". Journalism Studies, 1(1), pp.113-127.

Essén, A., (2008), "The two facets of electronic care surveillance: An exploration of the views of older people who live with monitoring devices". Social Science and Medicine, 67(1), pp.128-136.

European Commission, (2015), "Dementia", available at: http://ec.europa.eu/health/major_chronic_diseases/diseases/dementia_en (accessed April 23, 2017).

European Commission, (2007), "European i2010 initiative on e - Inclusion", available at: https://ec.europa.eu/digital-single-market/en/news/european-i2010-initiative-e-inclusionbe-part-information-society (accessed April 23, 2017).

European Parliament, (2011), "European Parliament resolution of 19 January 2011 on a European initiative on Alzheimer's disease and other dementias", available at: http://www.europarl.europa.eu/sides/getDoc.do?type=TA\&reference=P7-TA-20110016\&language $=$ EN (Accessed April 23, 2017).

European Parliamentary Research Service, (2016), "Need for action on dementia recalled", available at http://www.europarl.europa.eu/RegData/etudes/BRIE/2016/577959/EPRS_BRI(2016)57795 9_EN.pdf (accessed April 23, 2017).

Eurostat, (2015), "A look at the lives of the elderly in the EU today", available at http://ec.europa.eu/eurostat/cache/infographs/elderly/index.html (accessed April 24, 2018).

Fisk, M.J., (2015), "Surveillance technologies in care homes: seven principles for their use". Working with Older People, 19(2), pp.51-59.

Foucault, M., (2000), "Ethics: Subjectivity and Truth; The Essential Works of Michel Foucault", 1954-1984. Library Journal, 122, p.66.

Fuller, C., (1998), Caring for profit: How corporations are taking over Canada's health care system, Vancouver: New Star Books.

Futrell, M. \& Melillo, K.D., (2002), "Evidence-based protocol: wandering". Journal of Gerontological Nursing, 28(11), pp.14-22. 
Galea, A., Hough, E. \& Khan, I., 2017. "Test Beds the story so far", [gateway number 07200], NHS Englang, London.

Gibson, G., Newton, L., Pritchard, G., Finch, T., Brittain, K., \& Robinson, L. (2016), "The provision of assistive technology products and services for people with dementia in the United Kingdom". Dementia, 15(4), 681-701.

Goins, R., Kategile, U. \& Dudley, K., (2002), "Telemedicine, rural elderly, and policy issues". Journal of Aging \& Social Policy, 13(4), pp.53-71.

Goodwin, N., (2010), "The state of telehealth and telecare in the UK: prospects for integrated care". Journal of Integrated Care, 18(6), pp.3-10.

Graham, P., Evitts, T. \& Thomas-MacLean, R., (2008), "Environmental scans: how useful are they for primary care research?", Canadian Family Physician, Medecin de Famille Canadien, 54(7), pp.1022-3.

Graneheim, U.H., Norberg, A. \& Jansson, L., (2001), "Interaction relating to privacy, identity, autonomy and security. An observational study focusing on a woman with dementia and 'behavioural disturbances', and on her care providers". Journal of Advanced Nursing, 36(2), pp.256-265.

Hall, A., Wilson, C. B., Stanmore, E., \& Todd, C. (2017), "Implementing monitoring technologies in care homes for people with dementia: A qualitative exploration using Normalization Process Theory". International Journal of Nursing Studies, 72, 60-70.

Higgs, P. \& Gilleard, C., (2014), "Frailty, abjection and the 'othering' of the fourth age". Health Sociology Review, 23(1), pp.10-19.

van Hoof, J., Kort, H. S., Van Waarde, H., \& Blom, M. M (2010), "Environmental interventions and the design of homes for older adults with dementia: an overview". American Journal of Alzheimer's Disease and Other Dementias, 25(3), pp.202-232.

Hughes, R., (2008), "Electronic surveillance and tagging people with dementia". International Journal of Palliative Nursing, 14(5), p.74.

Hughes, R., (2008), "Using surveillance and tracking technology in care homes". Nursing And Residential Care, 10(7), pp.341-345.

Investopedia LLC, (2017), "Cottage Industry", available at:

https://www.investopedia.com/terms/l/labor-productivity.asp (accessed October 24, 2017).

Joyce, K. \& Mamo, L., (2006), "Graying the Cyborg, New directions in Feminist Analyses of Aging, Science and Technology". In T. M. Calasanti \& K. F. Slevin, eds. Routledge. New York, pp. 99-121.

Kamalasekar, S., (2010), "European remote patient monitoring market", available at: http://www.frost.com/sublib/display-report.do?bdata1/4aHROcDovL3d3dy 5mcm9zdC5jb20vcHJvZC9zZXJ2bGV0L3JlcG9ydC1icm9jaHVyZS5wYWc\%2FaWQ9TTVEQi0- 
wMSOwMCOWMCOWMEB\%2BQEJhY2tAfkAxMzYzODY1NjIxNzg2\&id1\%4M5DB-01-00-00-00 (accessed October 24, 2017)

Kenner, A.M., (2008), "Securing the elderly body: Dementia, surveillance, and the politics of "Aging in place". Surveillance \& Society, 5(3), pp.252-269.

Kessler, E.M. \& Schwender, C., (2012), "Giving dementia a face? The portrayal of older people with dementia in German weekly news magazines between the years 2000 and 2009". Journals of Gerontology, 67 B(2), pp.261-270.

Kleebpung, N., (2010), "Advertising and media literacy: young people and their understanding of the world of advertising in Australia and Thailand". Doctoral thesis, Victoria University.

Kodner, D., (2003), "Consumer-directed services: lessons and implications for integrated systems of care", International Journal of Integrated Care, 3(2).

Kubitschke, L., Cullen, K. \& Múller, S., (2010), ICT \& Ageing: European study on users, markets and technologies-Final report, Brussels.

Kümpers, S.N.S., (2005), "Steering integrated care in England and The Netherlands: The case of dementia care: a neo-institutionalist comparative study", Doctoral thesis, pp.1-264.

Landau, R. \& Werner, S., (2012), "Ethical aspects of using GPS for tracking people with dementia: recommendations for practice". International Psychogeriatrics, 24(3), pp.358366.

Lyons, A., (2000), "Examining media representations: Benefits for health psychology". Journal of Health Psychology, 5(3), pp.349-358.

Marr, J., (1989), "Electronic tagging". Nursing Standard, 4(54).

McHugh, J., Wherton, J. P., Prendergast, D. K., \& Lawlor, B. A. (2012), "Identifying opportunities for supporting caregivers of persons with dementia through information and communication technology". Gerontechnology, 10(4), pp.220-230.

McShane, R., Gedling, K., Kenward, B., Kenward, R., Hope, T., \& Jacoby, R. (1998), "The feasibility of electronic tracking devices in dementia: a telephone survey and case series". International Journal of Geriatric Psychiatry, 13(8), 556-563.

Mental Welfare Commission for Scotland (2005), "Safe to Wander? Principles and Guidance on Good Practice in Care for Residents with Dementia and Related Disorders where Consideration is being given to the Use of Wandering Technologies in Care Homes and Hospitals", Edinburgh.

Miller, E. A., Tyler, D. A., Rozanova, J., \& Mor, V. (2012), "National newspaper portrayal of US nursing homes: Periodic treatment of topic and tone". The Milbank Quarterly, 90(4), 725761. 
Mitra, A., Raymond, M.A. \& Hopkins, C.D., (2008), "Can consumers recognize misleading advertising content in a media rich online environment?", Psychology and Marketing, 25(7), pp.655-674.

Moffat, P., (2008), "Should we tag people with dementia?", International Journal of Palliative Nursing, 14(2), pp.56-56.

Mulvenna, M., Hutton, A., Coates, V., Martin, S., Todd, S., Bond, R., \& Moorhead, A. (2017), "Views of caregivers on the ethics of assistive technology used for home surveillance of people living with dementia". Neuroethics, 10(2), 255-266.

National Health Service and Community Care Act, (1990), "National Health Service and Community Care Act", London, HMSO, 74, 165-244.

Nelson, A., Powell-Cope, G., Gavin-Dreschnack, D., Quigley, P., Bulat, T., Baptiste, A. S., \& Friedman, Y. (2004), "Technology to promote safe mobility in the elderly". Nursing Clinics of North America, 39(3), 649-671.

Netherlands Enterprise Agency, (2018), "Advertising", available at

https://business.gov.nl/regulation/advertising/ (accessed April 24, 2018).

Niemeijer, A.R., (2015), Exploring good care with surveillance technology in residential care for vulnerable people. Doctoral thesis, VU, VU University Press.

Office for National Statistics, (2017), "Overview of the UK population", available at https://www.ons.gov.uk/peoplepopulationandcommunity/populationandmigration (accessed August 2, 2017).

Östlund, B., (2004), "Social science research on technology and the elderly-Does it exist?", Science Studies, 17(2), pp.44-62.

Percival, J. \& Hanson, J., (2006), "Big brother or brave new world? Telecare and its implications for older people's independence and social inclusion". Critical Social Policy, 26(4), pp.888-909.

Phillips, B. \& Zhao, H., (1993), "Predictors of assistive technology abandonment", Assistive Technology, 5(1), pp.36-45.

Phillipson, C., (1998), Reconstructing old age: New agendas in social theory and practice, Sage, 1998.

Plastow, N.., (2006), "Is big brother watching you? Responding to tagging and tracking in dementia care". The British Journal of Occupational Therapy, 69(11), pp.525-527.

Pollack, M.., (2005), "Intelligent technology for an aging population: The use of Al to assist elders with cognitive impairment". Al Magazine, 26(2), p.9

Reklamombudsmannen, (2017), "The Swedish Advertising Ombudsman", available at http://reklamombudsmannen.org/eng/ (accessed April 24, 2018). 
Rialle, V., Ollivet, C., Guigui, C., \& Hervé, C. (2008), "What do family caregivers of Alzheimer's disease patients desire in smart home technologies?", Methods of Information in Medicine, 47(01), 63-69.

Robinson, L., Hutchings, D., Corner, L., Finch, T., Hughes, J., Brittain, K., \& Bond, J. (2007), "Balancing rights and risks: Conflicting perspectives in the management of wandering in dementia", Health, Risk \& Society, 9(4), 389-406.

Robinson, L., Brittain, K., Lindsay, S., Jackson, D., \& Olivier, P. (2009), "Keeping In Touch Everyday (KITE) project: developing assistive technologies with people with dementia and their carers to promote independence", International Psychogeriatrics, 21(3), 494-502.

Rozanova, J., Miller, E.A. \& Wetle, T., (2016), "Depictions of nursing home residents in US newspapers: Successful ageing versus frailty", Ageing \& Society, 36, pp.17-41.

Sävenstedt, S., Sandman, P.O., \& Zingmark, K., (2006), "The duality in using information and communication technology in elder care", Journal of Advanced Nursing, 56(1), pp.17-25.

Schulz, R., Beach, S. R., Matthews, J. T., Courtney, K. L., \& Dabbs, A. J. D. V. (2012), "Designing and evaluating quality of life technologies: An interdisciplinary approach", Proceedings of the IEEE, 100(8), 2397-2409.

Schulz, R., (2012), Facilitators and Barriers to Technology Uptake. In Quality of Life Technology Handbook. CRC Press, London.

Seale, C., (2003), "Health and media: An overview". Sociology of Health and IIIness, 25(6), pp.513-531.

Steventon, A., Bardsley, M., Billings, J., Dixon, J., Doll, H., Beynon, M., Hirani, S., Cartwright, M., Rixon, L., Knapp, M., Henderson, C., Rogers, A., Hendy, J., Fitzpatrick, R., Newman, S (2013), "Effect of telecare on use of health and social care services: Findings from the Whole Systems Demonstrator cluster randomised trial", Age and Ageing, 42(4), pp.501-508.

Taylor, K., (2012), Primary care: Working differently telecare and telehealth - a game changer for health and social care. Technical report, Deloitte Centre for Health Solutions, available at http://www2. deloitte. com/content/dam/Deloitte/uk/Documents/life-scienceshealth-care/deloitte-uk-telehealth-telecare. pdf, 2012 (accessed 10 October 2017).

The Scottish Government., (2010), "Scotland's National Dementia Strategy", available at http://www.gov.scot/Publications/2010/09/10151751/0 (accessed 7 October 2017).

Topo, P., (2009), "Technology studies to meet the needs of people with dementia and their caregivers a literature review", Journal of Applied Gerontology, 28(1), pp 5-37

Walker, A., (2008), "Commentary: The emergence and application of active aging in Europe". Journal of Aging \& Social Policy, 21(1), pp.75-93.

Wan, L., Müller, C., Randall, D., \& Wulf, V. (2016), "Design of A GPS Monitoring System for Dementia Care and its Challenges in Academia-Industry Project", ACM Transactions on Computer-Human Interaction (TOCHI), 23(5), 31. 
Welsh Assembly Government \& Alzheimer Society (2011), National Dementia Vision for Wales-Dementia Supportive Communities, available at https://gov.wales/docs/dhss/publications/110302dementiaen.pdf (accessed 7 October 2017).

Welsh, S. Hassiotis, A., O'mahoney, G., \& Deahl, M., (2003), "Big brother is watching you-the ethical implications of electronic surveillance measures in the elderly with dementia and in adults with learning difficulties", Aging \& Mental Health, 7(5), pp.372-375.

Williamson, J. \& Skinner, C., (2011), "Death and illness as depicted in the media". International Journal of Clinical Practice, 65(5), pp.547-551.

Wimo, A., Winblad, B. \& Grafstrom, M., (1999), "The social consequences for families with Alzheimer's disease patients: Potential impact of new drug treatment", International Journal of Geriatric Psychiatry, 14(5), pp.338-347.

Woods, B., (1999), "Promoting well-being and independence for people with dementia", International Journal of Geriatric Psychiatry, 14(2), pp.97-105.

Woolrych, R., Sixsmith, A., Mortenson, B., Robinovitch, S., Feldman, F., (2013), "The nature and use of surveillance technologies in residential care", In Lecture Notes in Computer Science, Springer Berlin Heidelberg, pp. 1-9.

World Health Organization, (2012), Dementia a Public Health Priority, available at http://www.who.int/mental_health/publications/dementia_report_2012/en/ (accessed 5 October 2017).

\section{Acknowledgements}

The research presented in this article was carried out as part of the Marie Curie Innovative Training Network (ITN) action, H2020-MSCA-ITN-2015, under grant agreement number 676265. First, our thanks must go to the carers and people living with dementia who volunteered to comment on the presentations and provided invaluable comments and guidance throughout the study. We also would like to thank those involved in the Interdisciplinary Network for Dementia Using Current Technology (INDUCT). The early stage researchers, Alzheimer Nederland (The Netherlands), and the division of Occupational Therapy at the Karolinska Insitutet (Sweden). They all contributed to the search and keywords for this study. Especially Professor Louise Nygård, who acted as a specialist advisor to the project. We are all grateful to all of them. Finally, the anonymous referees who provided helpful comments on the draft paper which have improved this final version. 


\section{Biography}

Yvette Vermeer is an Early Stage Researcher at the Interdisciplinary Network for Dementia Using Current Technology (INDUCT) and a PhD student at University College London in the United Kingdom. Paul Higgs is a Professor of Sociology and Georgina Charlesworth is an Associate Professor, both at the faculty of Brain Sciences at University College London in the United Kingdom.

' Detection monitors that raise alerts are used to manage potential risk situations, for example when a person with dementia continues to use their own kitchen but is at risk of causing a fire by forgetting to turn off the gas to the stove. 